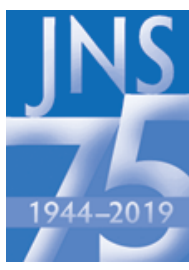

\title{
Surgery for nerve injury: current and future perspectives
}

\author{
JNSPG 75th Anniversary Invited Review Article
}

Rajiv Midha, MD, MSc, FRCSC, ${ }^{1}$ and Joey Grochmal, MD, PhD, FRCSC ${ }^{2}$

${ }^{1}$ Department of Clinical Neurosciences, Hotchkiss Brain Institute, Cumming School of Medicine, University of Calgary, Alberta, Canada; and ${ }^{2}$ Neurosurgery, University Medical Center, Lubbock, Texas

\begin{abstract}
In this review article, the authors offer their perspective on nerve surgery for nerve injury, with a focus on recent evolution of management and the current surgical management. The authors provide a brief historical perspective to lay the foundations of the modern understanding of clinical nerve injury and its evolving management, especially over the last century. The shift from evaluation of the nerve injury using macroscopic techniques of exploration and external neurolysis to microscopic interrogation, interfascicular dissection, and internal neurolysis along with the use of intraoperative electrophysiology were important advances of the past 50 years. By the late 20th century, the advent and popularization of interfascicular nerve grafting techniques heralded a major advance in nerve reconstruction and allowed good outcomes to be achieved in a large percentage of nerve injury repair cases. In the past 2 decades, there has been a paradigm shift in surgical nerve repair, wherein surgeons are not only directing the repair at the injury zone, but also are deliberately performing distal-targeted nerve transfers as a preferred alternative in an attempt to restore function. The peripheral rewiring approach allows the surgeon to convert a very proximal injury with long regeneration distances and (often) uncertain outcomes to a distal injury and repair with a greater potential of regenerative success and functional recovery. Nerve transfers, originally performed as a salvage procedure for severe brachial plexus avulsion injuries, are now routinely done for various less severe brachial plexus injuries and many other proximal nerve injuries, with reliably good to even excellent results. The outcomes from nerve transfers for select clinical nerve injury are emphasized in this review. Extension of the rewiring paradigm with nerve transfers for CNS lesions such as spinal cord injury and stroke are showing great potential and promise. Cortical reeducation is required for success, and an emerging field of rehabilitation and restorative neurosciences is evident, which couples a nerve transfer procedure to robotically controlled limbs and mind-machine interfacing. The future for peripheral nerve repair has never been more exciting.
\end{abstract}

https://thejns.org/doi/abs/10.3171/2018.11.JNS181520

KEYWORDS nerve grafting; nerve transfers; neurolysis; peripheral nerve

$\mathrm{P}$ ERIPHERAL nerve injuries have been recognized since antiquity. Management of nerve injuries, including nerve repair, have been described in various textbooks and reports from the Classical era, the Medieval era, in pre-Industrial times, and into the early 20th century (see the article by Friedman for a nice review of the topic ${ }^{37}$ ). For instance, Paul of Aegina (7th century) described the concepts of nerve repair and regeneration. With the advent and understanding of the nervous system in the mid-19th century, the description of the neuron as a single cell and its peripheral process, which undergoes the process of anterograde myelin degeneration (described beautifully by Waller in 1850), as well as the response of the peripheral versus the central nervous system to injury and regeneration by Cajal in 1905, provided the fundamental biological insights for an improved understanding of nerve injury and repair. The first successful nerve regeneration after surgical repair was reported by Cruikshank in 1795. Primary epineurial suturing and nerve suturing techniques were described by Heuter in 1871 and Mikulicz in 1882, respectively, while Albert in 1876 pioneered nerve grafting procedures to bridge nerve gaps. Further advances occurred during World War I and World War II, where a large number of nerve injuries were encountered and attempts of repair were undertaken. Many of these early forms of management involved exploration of

ABBREVIATIONS AIN = anterior interosseous nerve; $\mathrm{CN}=$ cranial nerve; $\mathrm{PIN}=$ posterior interosseous nerve; $\mathrm{SSN}=$ suprascapular nerve.

SUBMITTED November 6, 2018. ACCEPTED November 6, 2018.

INCLUDE WHEN CITING DOI: 10.3171/2018.11.JNS181520. 
the wound, wide debridement, and repair of nerve under tension (sometimes accompanied by limb shortening or splinting the extremities in a flexed posture for months) with relatively poor results and an occasional success. Improved understanding of the pathology of nerve injury and nerve injury in continuity derived from the World War II experience. ${ }^{62}$

With the subsequent use of nerve autograft techniques, we enter the more modern era of nerve injury repair. Pioneering work by Hanno Millesi and colleagues in the 1960s with the use of interfascicular nerve grafting to avoid tension at the repair and good microsurgical technique (aided by magnification) was a major landmark in the nerve repair era. ${ }^{56}$ The use of intraoperative nerve monitoring with the use of nerve action potential studies and their utilization to resect an injury neuroma and graft versus neurolysis alone was a fundamental insight provided by David Kline and colleagues to help surgeons manage the majority of nerve injuries in continuity encountered in clinical practice. ${ }^{44} \mathrm{~A}$ combination of the neurophysiological work by Kline and the microsurgical insights of graft repair without tension by Millesi led to significant improvements in the outcomes of nerve repair in the 1960s and the 1970s. With the use of the operating microscope and these aids, the microsurgical era of nerve repair was fully established in the past 2 generations. As these techniques were adopted and used by the large cadre of peripheral nerve surgeons worldwide, the results from peripheral nerve repair quickly plateaued in the 1980s and 1990s. Indeed, an honest appraisal of these results can be found in various excellent textbooks including those from Kline's extensive experience and from the excellent review by Brushart, and critical reading of these underscores that approximately $50 \%-75 \%$ of patients have modest recoveries from nerve injury repair by grafting. ${ }^{22,42}$

\section{Timing of Nerve Exploration and Repair}

The mechanism and severity of nerve injury determines the possibility of recovery and the need for nerve exploration (Fig. 1). Every peripheral nerve injury in which there is complete nerve damage that will require axonal regeneration and reinnervation is a form of chronic nerve injury. This is because the rate of regeneration in humans is approximately $1 \mathrm{~mm} /$ day, and the distance to target end organs from the area of nerve injury is quite lengthy. This renders the distal nerve zone as well as the muscle end organ or the sensory receptor to be chronically denervated. A large body of animal literature as well as circumstantial patient literature with regard to timing of nerve repair and outcomes underscores the fact that outcomes are greatly improved when nerve repair is undertaken earlier. ${ }^{72}$ However, if a nerve can regenerate satisfactorily on its own (Sunderland grade 2 injuries and some grade 3 injuries), then the outcome of spontaneous recovery is generally excellent, compared with the modest outcomes of nerve repair. For this reason, most surgeons wait several months before undertaking exploration of nerve injuries in continuity, and appropriately so. In a few (especially European) centers, there has been a shift toward very early exploration and reconstruction. This represents the minority of clinical experience. There has been a gradual and appropriate shift in timing of nerve exploration and possible reconstruction, with an emphasis on intervening earlier, particularly in patients with clinically complete and severe brachial plexus injuries. The dogma of waiting for many months or up to $6-8$ months is no longer tenable, and the majority of reconstructive peripheral nerve surgeons now plan to operate on these patients within a few weeks to months from the time of injury.

Imaging revolutionized the diagnosis and management of most aspects of neurosurgery, as well as nerve tumors. Its utility in managing nerve trauma has been less spectacular. The use of improved imaging techniques, especially high-quality ultrasound and MRI, does allow for a better visualization of the area of nerve injury, particularly to image nerve disconnection and/or likely laceration. Indeed, resolution of ultrasound in particular can render the anatomical details of nerve discontinuity at even a fascicular level. A good and practical use of ultrasound is as an adjunct to shape overall management in cases of uncertainty if a nerve is in discontinuity, such as a shrapnel-associated injury or a penetrating nerve injury, such as that associated with gunshot wounds. However, no imaging modality yet allows sufficient spatial resolution to predict whether a sufficient aliquot of nerve fibers is regenerating through the neuroma in continuity, enough to mitigate against surgical evaluation with operating microscope magnification, interfascicular dissection, and use of intraoperative electrophysiology. Hence, the current management of most nerve injuries is the following. For nerves that are clearly lacerated or likely to be lacerated, immediate or very early exploration is recommended. For injuries in which the nerve is likely lacerated in a blunt fashion (for example, a boat propeller injury), delayed exploration and secondary nerve repair with appropriate placement of nerve grafts at approximately 3-4 weeks is warranted. With most nerve injuries, a period of watchful waiting is recommended. For high-velocity severe traction injuries and/or very proximal brachial plexus injuries, earlier exploration after several weeks is recommended, whereas with low-velocity injuries such as fracture-associated palsies, a somewhat conservative approach is initially taken with serial clinical and electrophysiological evaluation for recovery. If recovery does not start to manifest after 3-4 months, nerve exploration is undertaken. While some European centers advocate for acute brachial plexus exploration, we remain without any significant level of evidence for operating ultra early versus in a somewhat delayed fashion for the majority of brachial plexus injuries.

\section{Nerve Repair in the Modern Era: Nerve Transfers}

Improved outcomes from nerve repair essentially required a paradigm shift, which we are now witnessing with the advent and the increased popularity of nerve transfer techniques. A nerve transfer technique essentially involves repair of the distal denervated nerve element by an adjacent foreign donor nerve. These nerve transfers are usually done far distally, beyond the area of original nerve injury and close to the end organ, thereby converting a 


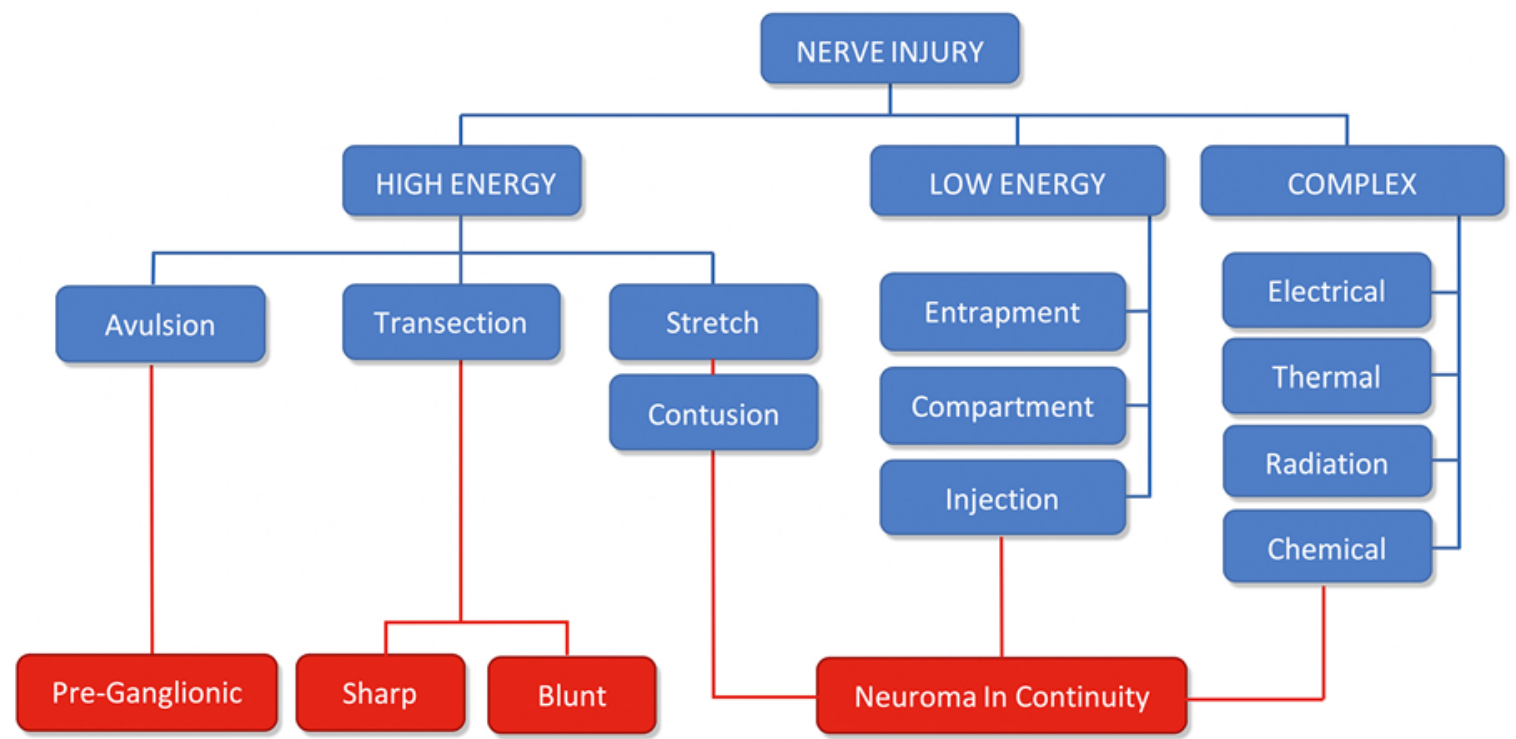

FIG. 1. Scheme to evaluate patients with nerve injury by mechanism. The likelihood of severe nerve injury and thus lack of spontaneous recovery with resulting need for surgical exploration and nerve reconstruction are much greater for high-energy mechanisms. Figure modified, with permission, from Shapira Y, Midha R: Pathophysiology of surgical nerve disorders, in Filler A, Belzberg AJ, Chen L, Malessy M (eds): Youmans and Winn's Neurological Surgery, ed 7. Philadelphia: Elsevier, 2017, Vol 3, pp 1966-1977 (Figure 244-2). ${ }^{72}$ Figure is available in color online only.

proximal nerve injury, with long regeneration distances and uncertain outcomes, to a more distal repair from which recovery is theoretically faster and more robust.

The advent of the modern nerve transfer era began arguably in the early 1990s with a series of papers that began to explore the possibility of neurotization in severe plexus injury using an extraplexal donor nerve such as the intercostals, the spinal accessory nerve, the phrenic nerve, and the medial pectoral nerve. ${ }^{21,28,40,59,68}$ In 1994, Oberlin published his now seminal paper detailing the transfer of an ulnar fascicle to the biceps motor nerve for reanimation of elbow flexion. ${ }^{63}$ The success of this relatively simple procedure transformed the collective thinking that had previously regarded nerve transfers as a salvage-only procedure. Several caveats for success include choosing a donor nerve that has redundant function to other preserved nerves so that there is no significant downgrading of function in the patient. Interfascicular dissection so that single fascicles are chosen as donors again decreases the possibility of functional complications. Parenthetically, the popularity of fascicular transfers has offered a renaissance to the surgeon to apply the techniques of internal neurolysis, which historically were used for intraneural dissection for some nerve injuries (Fig. 2). Moreover, the use of nerve transfers also ensures that the specificity of the element being transferred is controlled by the surgeon (using neuroanatomical and neurophysiological knowledge), along with choosing a synergistic donor/recipient combination so that cortical reeducation is possible. The success of nerve transfers is largely facilitated by cortical plasticity, which has been repeatedly demonstrated in the context of nerve transfer rehabilitation. ${ }^{2,41,57,73,86}$ Other factors known to influence success of nerve transfer are donor size matching with the recipient nerve and the robustness of preoperative electromyography-detected activity from the donor nerve/muscle. ${ }^{69,70}$ For example, the optimal donor-to-nerve axon count ratio for elbow flexion seems to be $>0.7: 1.69$

What follows is a commentary on the state of the art for nerve transfers and restoration of function of the upper extremity, including current controversies. It should be noted that the efficacy of nerve transfers has been reviewed several times in detailed systematic analysis. ${ }^{38,85}$ In general, it has been well accepted that in the context of upper plexus injury involving multiple roots, nerve transfers are superior and more reliable to grafting techniques for the recovery of both elbow flexion and shoulder abduction. ${ }^{1,74}$ Direct end-to-end neurotizations perform better than transfers requiring interposition grafts. ${ }^{38,82}$ In addition, the more extensive the plexus injury, the poorer the recovery. ${ }^{15,23}$

\section{Shoulder Function}

Early work on nerve transfers for shoulder function focused on neurotization of the suprascapular nerve (SSN) and axillary nerve, primarily with accessory and phrenic nerve donors. ${ }^{27,31,55,59,68}$ There has been progressive proof that double neurotization of the SSN and axillary nerve provides best results (Table 1). ${ }^{47,49,55,80}$ This is in the context of the commonly utilized triple nerve transfer (accessory nerve to SSN, triceps motor nerve to axillary nerve, ulnar nerve fascicle to biceps motor nerve), which is becoming the standard choice for nerve reconstruction for upper plexus injury. ${ }^{11,15,38}$

When compared directly with plexus graft repair, nerve transfers have fared either equal to or better than grafting for restoration of shoulder function. ${ }^{38,85}$ Recovery of shoulder abduction is often greater than $90^{\circ},{ }^{15,46}$ with a significant proportion of patients regaining a Medical Research 

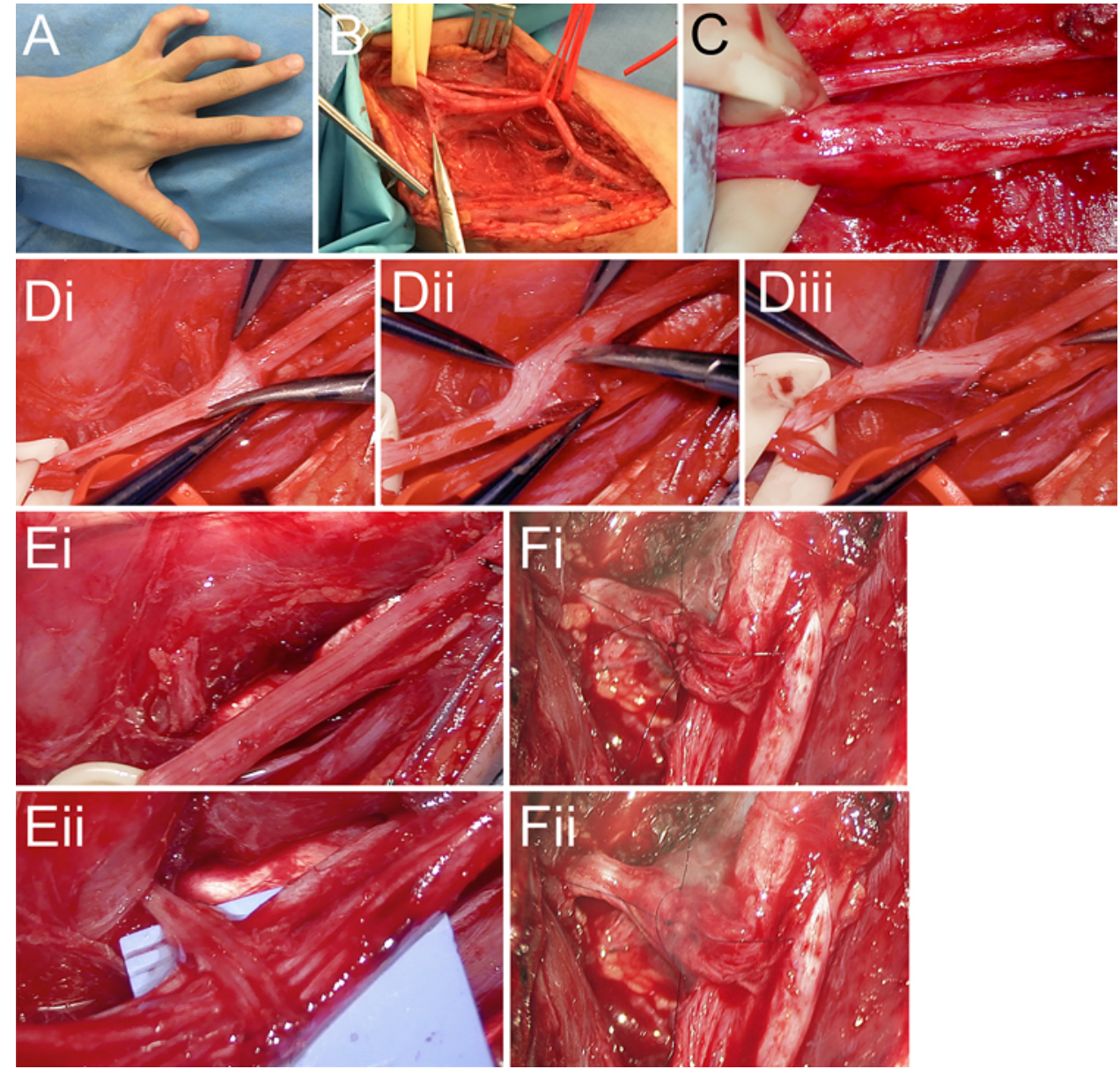

FIG. 2. A young woman had sustained a blunt contusion to the medial arm several months earlier, resulting in a clinically complete ulnar nerve injury, with atrophy of the interossei muscles and claw-hand positioning (A). Intraoperative photographs demonstrate external neurolysis (B) to reveal a focal neuroma in continuity (C). Internal neurolysis, using microsurgical techniques and operative microscopic magnification, with epineurotomy (Di), and intraneural dissection (Dii) revealed fascicular continuity (Diii). Electrical stimulation produced a small nerve action potential across the lesion and EMG discerned forearm muscle contraction, although this was not clinically apparent. Given the presence of likely spontaneous regeneration from the original injury, an endto-side transfer was performed from the end of the motor pronator quadratus fascicle of the anterior interosseous nerve (Ei) to the side of the motor fascicle of the ulnar nerve in the distal forearm (Eii), in an attempt to augment functional recovery. In a different case with zero possibility of regeneration from a very proximal severe ulnar nerve lesion, we choose to do an end-to-end repair from the pronator quadratus fascicle to the ulnar motor fascicle (Fi), with the repair reinforced with fibrin glue (Fii), to restore some ulnar nerve-related hand function. Figure is available in color online only.

Council grade $\geq$ M4 deltoid strength. External rotation outcomes are less impressive. ${ }^{46}$ Although it is often not quantified in the literature, a major goal for shoulder reinnervation surgery is the restoration of shoulder stability, which happens in the majority of cases where the suprascapular nerve is neurotized.

There is still a strong argument to be made for primary graft repair of the injured nerve element. An example is the relatively common axillary nerve injury that occurs from shoulder dislocation, with pathology typically starting at the level of the posterior cord in the axilla at the emergence of the axillary nerve and then for a variable distance into the quadrangular space as the nerve traverses from an anterior to a posterior location before entering into the deltoid muscle. Many of these injuries do recover spontaneously. For the ones that do not, the traditional management has been to explore the nerve, usually with resection of the intervening neuroma and long graft repairs. The outcomes from such repairs are relatively good for deltoid recovery. Yet many of these injuries are now being repaired surgically with the seemingly more simple technique of doing a posterior exploration of the axillary nerve and then transferring one of the triceps branches to one of the divisions of the axillary nerve. This transfer has a highly reliable recovery of function, but one could argue that this is not better than, and perhaps not even as good as, the traditional reconstructive approach. ${ }^{4}$ Unfortunately, there is no level 1 or even level 2 evidence to guide us as to what is the appropriate approach between these 2 very alternative reconstructive strategies for pure axillary nerve injuries.

In isolated axillary injury, grafting has recently been found to be superior to nerve transfer for optimal recovery. ${ }^{4}$ In plexus-level injuries, Bertelli and Ghizoni found 
TABLE 1. Nerve transfers for shoulder reanimation: selected studies

\begin{tabular}{|c|c|c|c|c|c|}
\hline Authors \& Year & LOE & No. of Pts & Indication & Procedure & Outcome \\
\hline Baltzer et al., 2016 & III & 29 & $\begin{array}{l}\text { Isolated axillary } \\
\text { nerve injury }\end{array}$ & $\begin{array}{l}\text { Triceps motor nerve } \rightarrow \text { axillary nerve } \\
\text { vs grafting }\end{array}$ & Grafting better than $\mathrm{TX}$ for $\mathrm{MRC} \geq 3$ \\
\hline Yang et al., 2012 & II & 615 & $\begin{array}{l}\text { Upper plexus } \\
\text { injury }\end{array}$ & $\begin{array}{l}\text { Various neurotization of SSN \& axil- } \\
\text { lary nerve vs graft }\end{array}$ & Transfers equal to grafting for MRC $\geq 3$ Sabd \\
\hline Garg et al., 2011 & II & 56 & $\begin{array}{l}\text { Upper plexus } \\
\text { injury }\end{array}$ & $\begin{array}{l}\text { Various neurotization of SSN \& axil- } \\
\text { lary nerve vs graft }\end{array}$ & $\begin{array}{l}\text { Dual TX for Sabd better than single TX or } \\
\text { grafting }\end{array}$ \\
\hline $\begin{array}{l}\text { Bertelli \& Ghizoni, } \\
\quad 2010^{8}\end{array}$ & III & 37 & C5-6 palsy & $\begin{array}{l}3 \text { TX vs C5 graft + } 3 \text { TX vs C5-6 graft } \\
\quad+\mathrm{CN} \mathrm{XI} \rightarrow \text { SSN + Oberlin }\end{array}$ & Best results $w / 3 \mathrm{TX}+$ graft \\
\hline $\begin{array}{l}\text { Bertelli \& Ghizoni, } \\
\quad 2007\end{array}$ & IV & 30 & $\begin{array}{l}\text { Various severity } \\
\text { BPI }\end{array}$ & $\begin{array}{l}\mathrm{CN} \mathrm{XI} \rightarrow \text { SSN +/- triceps motor nerve } \\
\quad \rightarrow \text { axillary nerve }\end{array}$ & $\begin{array}{l}45^{\circ} \text { Sabd for total palsy; } 105^{\circ}-122^{\circ} \text { for upper } \\
\text { BPI }\end{array}$ \\
\hline Terzis et al., 2006 & IV & 92 & $\begin{array}{l}\text { Upper \& total } \\
\text { BPI }\end{array}$ & $\begin{array}{l}\text { Various neurotization of SSN \& axil- } \\
\text { lary nerve }\end{array}$ & $\begin{array}{l}\text { Combined SSN \& axillary nerve TX superior, } \\
79 \% \text { good outcome }\end{array}$ \\
\hline $\begin{array}{l}\text { Bertelli \& Ghizoni, } \\
\quad 2004^{11}\end{array}$ & IV & 10 & C5-6 palsy & $\begin{array}{l}\mathrm{CN} \mathrm{XI} \rightarrow \text { SSN, triceps motor nerve } \rightarrow \\
\quad \text { axillary nerve, Oberlin }\end{array}$ & $\begin{array}{l}100 \% \text { Sabd recovery, } 3 / 10 \text { grade } M 4,7 / 10 \text { grade } \\
\text { M3 }\end{array}$ \\
\hline $\begin{array}{l}\text { Leechavengvongs } \\
\text { et al., } 2003\end{array}$ & IV & 7 & $\begin{array}{l}\text { Upper plexus } \\
\text { injury }\end{array}$ & $\begin{array}{l}\text { Triceps motor nerve } \rightarrow \text { axillary nerve, } \\
\quad \mathrm{CN} \mathrm{XI} \rightarrow \text { SSN }\end{array}$ & All pts $\geq \mathrm{M} 4$ recovery of deltoid \\
\hline Merrell et al., 2001 & I & 123 & Various BPI & Neurotization of SSN vs axillary nerve & SSN better than axillary nerve for return of Sabd \\
\hline Merrell et al., 2001 & IV & 15 & Various BPI & $\begin{array}{l}\mathrm{CN} \mathrm{XI} \text { or intercostal nerves } \rightarrow \mathrm{SSN} \text { or } \\
\text { axillary nerve }\end{array}$ & Double TX more effective for recovery of Sabd \\
\hline
\end{tabular}

$\mathrm{BPI}=$ brachial plexus injury; LOE = level of evidence; MRC = Medical Research Council; pts = patients; Sabd = shoulder abduction; TX = transfer; +/- = with or without.

grafting and nerve transfer superior for shoulder recovery compared with nerve transfer alone. ${ }^{8}$ This was the preferred technique of Kline, the "belt and suspenders" approach intended to maximize axonal reinnervation of target musculature. ${ }^{45}$

\section{Elbow Flexion and Extension}

Restoration of elbow flexion, along with shoulder stabilization, is a primary goal of any plexus repair or nerve transfer surgery for upper or total plexus injury. Many donors have been used to neurotize the musculocutaneous (or biceps motor) nerve, including the phrenic nerve, ${ }^{40,58,68}$ intercostal nerves, ${ }^{28,29,58,68}$ medial pectoral nerve, ${ }^{21}$ accessory nerve,$^{76}$ thoracodorsal nerve, ${ }^{61}$ and contralateral C7 nerve. ${ }^{81}$ These procedures are effective and seem to provide a reasonable chance for the patient to regain grade $\geq$ M3 biceps strength (Table 2). 19,59,68 They remain invaluable additions to the toolbox for reconstruction of total plexus injury; however, in cases of upper plexus injury, the Oberlin transfer has become standard of care. The procedure, which involves the transfer of an ulnar nerve fascicle to the biceps motor nerve, reliably produces grade $\geq \mathrm{M} 4 \mathrm{el}-$ bow flexion in a large proportion of patients. ${ }^{48,63}$ Young patients with isolated upper plexus injury and an intact hand fare best. ${ }^{32}$ Short regeneration distance means that this procedure can be effective, even after delayed presentation ( $>6$ months from injury). ${ }^{71}$ Alternatively, nonessential median nerve branches to wrist and finger flexors

TABLE 2. Nerve transfers for restoration of elbow flexion: selected studies

\begin{tabular}{|c|c|c|c|c|c|}
\hline Authors \& Year & LOE & No. of Pts & Indication & Procedure & Outcome \\
\hline Cho et al., 2014 & III & 24 & Upper plexus injury & Ulnar vs median nerve $\rightarrow$ biceps motor nerve & Equal outcomes \\
\hline Martins et al., 2013 & III & 40 & Upper plexus injury & Reinnervation of biceps vs biceps \& brachialis & No difference in clinical outcome \\
\hline Socolovsky et al., 2012 & III & 35 & Upper plexus injury & Graft vs Oberlin & Oberlin was superior for EF \\
\hline Coulet et al., 2010 & III & 40 & C5-6 +/- C7 palsy & Ulnar fascicle vs intercostal nerves $\rightarrow$ MCN & Ulnar fascicle TX superior for EF \\
\hline Bertelli \& Ghizoni, $2010^{8}$ & III & 37 & C5-6 palsy & $\begin{array}{l}3 \text { TX vs C5 graft }+3 \text { TX vs C5-6 graft }+ \text { CN II } \\
\quad \rightarrow \text { SSN + Oberlin }\end{array}$ & $\begin{array}{l}\text { Best results w/ C5-6 graft + } \\
\text { Oberlin }\end{array}$ \\
\hline Mackinnon et al., 2005 & IV & 6 & Upper plexus injury & $\begin{array}{l}\text { Ulnar nerve } \rightarrow \text { biceps motor nerve; median } \\
\text { nerve } \rightarrow \text { brachialis nerve }\end{array}$ & Average $\geq \mathrm{M} 4$ recovery EF \\
\hline Ferraresi et al., 2004 & IV & 43 & C5-7 avulsion & Ulnar or median nerve $\rightarrow$ biceps motor nerve & M2-M4 recovery \\
\hline $\begin{array}{l}\text { Leechavengvongs et al., } \\
1998\end{array}$ & IV & 32 & Upper plexus injury & Ulnar fascicle $\rightarrow$ biceps motor nerve & $30 / 32$ w/ M4 EF \\
\hline Nagano et al., 1995 & IV & 112 & Upper \& total BPI & Intercostal nerves $\rightarrow$ MCN & $87 \%$ regained $\geq \mathrm{M} 3 \mathrm{EF}$ \\
\hline Oberlin et al., 1994 & IV & 4 & C5-6 avulsion & Ulnar fascicle $\rightarrow$ biceps motor nerve & $100 \% \geq \mathrm{M} 3 ; 75 \% \mathrm{M} 4 \mathrm{EF}$ \\
\hline
\end{tabular}

$\mathrm{EF}=$ elbow flexion; $\mathrm{MCN}=$ musculocutaneous nerve. 


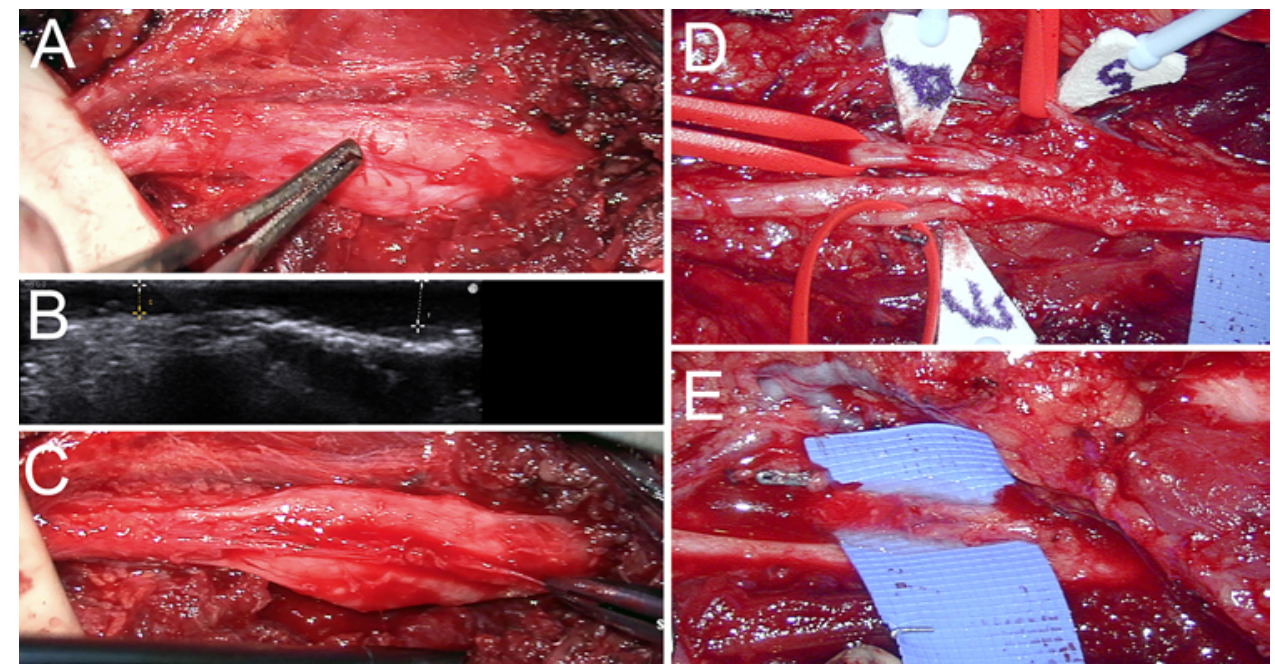

FIG. 3. In a young man 6 months after spontaneous painless onset of a clinically complete and nonrecovering posterior interosseous nerve (PIN) palsy, the PIN was decompressed at the arcade of Frohse and supinator muscle to show focal swelling of the nerve. A-C: Intraoperative ultrasonography study demonstrating the enlarged nerve (compare the dashed line on the right with the dashed line on the left; A), lacking clear fascicular structure (B), which after epineurotomy revealed a couple of large, somewhat firm fascicles (C). D: In a different case of complete C6 quadriplegia, external and internal neurolysis of the radial nerve branches in the proximal forearm is performed, followed by electrical stimulation confirmation, for branches to the supinator (S), extensor carpi radialis brevis $(E)$, and finger extensors or distal PIN (P). E: Since this patient had normal supination (preserved biceps and supinator muscles), but lacked finger extension (via the PIN), it was elected to sacrifice supinator muscle innervation by performing transfers from both supinator fascicles to the PIN to restore finger extension. Figure is available in color online only.

have been used as donors for the biceps or brachialis motor nerve. ${ }^{78}$ Median to biceps motor nerve transfer produces near equivalent elbow flexion recovery compared to the Oberlin procedure. ${ }^{26}$

Many authors have purported the use of a double fascicular transfer in elbow flexion restoration, a procedure that involves both a classic Oberlin transfer (ulnar fascicle to biceps motor) as well as median nerve transfer to the nerve innervating the brachialis. Proponents of this technique, such as Mackinnon et al., point to the excellent outcomes it very often achieves, as well as the lack of functional median nerve deficit postoperatively. ${ }^{52,66}$ However, a recent prospective study found no clinical difference in recovery of elbow flexion between patients who received a single nerve transfer to the biceps motor nerve and those who received a double transfer that also included reinnervation of the brachialis. ${ }^{54}$ Therefore, the double fascicular transfer for restoration of elbow flexion remains a topic of controversy among experts in the field.

Restoration of elbow extension is often a secondary goal to provide greater elbow control via antagonistic feedback to the elbow flexors. ${ }^{35}$ In avulsions, phrenic or intercostal nerves are suitable donors to the radial triceps motor nerve. ${ }^{36,39}$ In isolated lower plexus injury, intact radial fascicles, thoracodorsal nerve, or nerve to brachialis have all recently demonstrated efficacy in restoring functional elbow extension. ${ }^{16,34,75}$

\section{Hand and Wrist Reanimation}

In situations in which hand and wrist function have been affected by lower plexus injury, spinal cord injury, or proximal nerve injury, nerve transfers are increasingly indicated, thanks to much recent work in this field.

In high ulnar injury, and likewise in cubital tunnel syndrome with severe end-stage axonopathy, the distal anterior interosseous nerve (AIN) branch to pronator quadratus has become a popular donor for reinnervation of the distal ulnar motor branch (Fig. 2) ${ }^{60}$ The outcomes for this procedure may be superior to proximal ulnar grafting for both motor and functional hand outcomes. ${ }^{33,67}$ Of note, some authors have suggested the use of the end-to-side or "supercharge" repair, in which the distal AIN is grafted onto the side of the ulnar motor branch while maintaining the continuity of the proximal ulnar nerve (Fig. 2). ${ }^{30}$

Nerve transfers in spinal cord injury are an exciting advancement and a relatively new territory, though sporadic efforts have been previously attempted. ${ }^{43}$ Nerve transfers for treatment of lower plexus injury overlap significantly with those used in spinal cord injury patients, particularly in midcervical spinal cord injury. The concept is to use intact donor nerves to give the patient function in myotomes distal to the level of injury. The donors and recipients for these transfers are variable and individualized to the patient, and depend on the presence or absence of viable donors as well as functional goals. An emerging theme is the use of nerves to the supinator and the extensor carpi radialis brevis to innervate the posterior interosseous nerve (PIN) and AIN, respectively (Fig. 3). ${ }^{10,14}$ Procedures of this type are listed in Table 3; of note is the pioneering work of Bertelli and colleagues in this field..$^{5,9,17}$

\section{Flail Arm}

Reconstruction of total plexus avulsion remains a significant challenge and was the original indication for nerve transfer surgery. ${ }^{59}$ Available extraplexal donors include cranial nerves (CNs) $\mathrm{XI}^{7,55,76}$ and $\mathrm{XII}$, the contralateral $\mathrm{CN}$ $\mathrm{XI},{ }^{18}$ intercostal nerves, ${ }^{59,64}$ the phrenic nerve,,${ }^{40,51}$ and the contralateral C7 (Table 4). ${ }^{82}$ Primary goals include restora- 
TABLE 3. Nerve transfers for restoration of hand and wrist function: selected studies

\begin{tabular}{|c|c|c|c|c|c|}
\hline Authors \& Year & LOE & No. of Pts & Indication & Procedure & Outcome \\
\hline Sallam et al., 2017 & III & 52 & Proximal ulnar injury & Grafting vs AIN $\rightarrow$ ulnar motor nerve & Improved strength \& grip in TX group \\
\hline Bertelli \& Ghizoni, 2017 & IV & 9 & Midcervical SCl & $\begin{array}{l}\text { Various donors to AIN or finger flexor } \\
\text { motor nerve }\end{array}$ & $\begin{array}{l}\text { All work, nerve to ECRB is superior } \\
\text { donor to AIN }\end{array}$ \\
\hline Bertelli \& Ghizoni, 2016 & IV & 28 & C5-8 root lesions & AIN $(P Q) \rightarrow$ ECRB & 25/28 M4 WE \\
\hline Davidge et al., 2015 & IV & 55 & Proximal ulnar injury & AIN $(P Q) \rightarrow$ ETS ulnar motor nerve & $\begin{array}{l}\text { Improved grip, pinch, 1st DI strength, } \\
\text { \& self-report scores }\end{array}$ \\
\hline Flores, 2015 & III & 35 & Proximal ulnar injury & $\begin{array}{l}\text { AIN }(P Q) \rightarrow \text { ETE ulnar motor nerve } \\
\quad \text { vs grafting }\end{array}$ & $\begin{array}{l}\text { Improved motor \& functional out- } \\
\text { comes in TX group }\end{array}$ \\
\hline Bertelli \& Ghizoni, 2015 & IV & 20 & $\mathrm{SCl}$ & $\begin{array}{l}\text { Deltoid branch } \rightarrow \text { triceps nerve; } \\
\quad \text { supinator nerve } \rightarrow \text { PIN }\end{array}$ & $\begin{array}{l}\text { High proportion of M4 recovery of } \\
\text { EE, ThE, FE }\end{array}$ \\
\hline Bertelli et al., 2010 & IV & 1 & SCI, WE intact & Supinator nerve $\rightarrow$ PIN & M4 + FE, ThE \\
\hline Bertelli \& Ghizoni, $2010^{14}$ & IV & 4 & C7-T1 palsy & Supinator nerve $\rightarrow$ PIN & Restoration of FE, ThE \\
\hline Novak \& Mackinnon, $2002^{60}$ & IV & 8 & High ulnar injury & AIN $(P Q) \rightarrow$ ulnar motor nerve & $\begin{array}{l}8 / 8 \text { improved pinch, grip, EMG- } \\
\text { discerned reinnervation }\end{array}$ \\
\hline
\end{tabular}

$\mathrm{DI}$ = dorsal interosseous; $\mathrm{ECRB}$ = extensor carpi radialis brevis; $\mathrm{EE}$ = elbow extension; EMG = electromyography; $\mathrm{ETE}$ = end-to-end; ETS = end-to-side; FE = finger extension; $\mathrm{PQ}=$ pronator quadratus; $\mathrm{SCl}$ = spinal cord injury; $\mathrm{ThE}=$ thumb extension; $\mathrm{WE}=$ wrist extension.

tion of shoulder stability and abduction, as well as elbow flexion. ${ }^{27}$ Secondary goals are the recovery of elbow extension, along with wrist and hand function. Of note, intercostal donors may give better elbow flexion outcomes if grafted directly on to the biceps motor branch, ${ }^{25,53}$ and only 2 intercostal nerves may be sufficient for restoration of elbow flexion, ${ }^{83}$ although most authors use 3 . The use of the contralateral $\mathrm{C} 7$ root has yielded inconsistent results, ${ }^{79}$ and classically the procedure requires the use of a long interpositional graft. Recent technique advances do show promise to improve these outcomes, by both using a prespinal route to tunnel the $\mathrm{C} 7$ donor across midline, and in extreme circumstances, to achieve a tension-free primary repair with the lower trunk by shortening the humerus of the affected side..$^{20,82,84}$ These procedures are not without complications, in particular up to a $5.4 \%$ incidence of vertebral artery laceration. ${ }^{50}$

\section{Evolution of Nerve Surgery Repair: Transfers and Beyond}

The evolution of peripheral nerve surgery from one of exploration, neuroanatomical dissection, and reconstruction of the nerve injury site itself to one where essentially a peripheral rewiring procedure is carried out represents a fundamental shift in the repair of peripheral nerve injury that continues to evolve rapidly in the past 2 decades. While there had been some interest in managing nerve

TABLE 4. Nerve transfers for flail arm: selected studies

\begin{tabular}{|c|c|c|c|c|c|}
\hline Authors \& Year & LOE & No. of Pts & Indication & Procedure & Outcome \\
\hline Bhatia et al., 2017 & IV & 22 & Severe BPI & $\begin{array}{l}\text { Contralat } \mathrm{C} 7 \text { nerve direct repair vs } \\
\text { interposition graft }\end{array}$ & Better grade (M3) WF w/ direct repair \\
\hline Xiao et al., 2014 & III & 30 & Total BPI & 2 vs 3 vs 4 intercostal nerves $\rightarrow$ MCN & 2 intercostals are sufficient \\
\hline Wang et al., 2013 & IV & 75 & Severe BPI & $\begin{array}{l}\text { Contralat C7 nerve } \rightarrow \text { lower trunk } \\
\quad \text { (arm shortening) }\end{array}$ & $\geq \mathrm{M} 3 \mathrm{FF}(64 \%), \operatorname{ThF}(53 \%), \operatorname{WF}(72 \%)$ \\
\hline Lin et al., 2012 & IV & 6 & Plexus avulsion & $\begin{array}{l}\text { Full-length phrenic nerve } \rightarrow \text { radial } \\
\text { nerve }\end{array}$ & $5 / 6 \mathrm{w} / \geq \mathrm{M} 3 \mathrm{WE}, 4 / 6 \mathrm{w} / \geq \mathrm{M} 3 \mathrm{FE}$ \\
\hline $\begin{array}{l}\text { Terzis \& Kokkalis, } \\
2009\end{array}$ & IV & 56 & $\begin{array}{l}\text { Severe avulsion } \\
\text { BPI }\end{array}$ & $\begin{array}{l}\text { Contralat } \mathrm{C} 7 \text { nerve } \rightarrow \mathrm{MCN} \text { or axil- } \\
\quad \text { lary, radial, or median nerve }\end{array}$ & $\begin{array}{l}\geq \mathrm{M} 3 \text { Sabd } 20 \%, \text { EF } 52 \%, \text { ThE } 24 \%, \text { WE/FE } \\
\quad 20 \%, \text { WF/FF } 34 \%\end{array}$ \\
\hline $\begin{array}{l}\text { Bertelli \& Ghizoni, } \\
\quad 2004^{7}\end{array}$ & IV & 24 & $\begin{array}{l}\text { Avulsion BPI, } \\
\text { various }\end{array}$ & $\begin{array}{l}\text { Ulnar nerve vs CN XI vs phrenic nerve } \\
\quad \rightarrow \text { biceps motor nerve }\end{array}$ & Good EF recovery for all donors, mainly M4 \\
\hline $\begin{array}{l}\text { Songcharoen et al., } \\
1996\end{array}$ & IV & 216 & Avulsion BPI & $\mathrm{CN} \mathrm{XI} \rightarrow \mathrm{MCN}$ & $72.5 \% \mathrm{w} / \geq \mathrm{M} 3 \mathrm{EF}$ \\
\hline Chuang et al., 1995 & III & 99 & $\begin{array}{l}\text { Upper \& total } \\
\text { BPI }\end{array}$ & Various donor \& recipient nerves & $\begin{array}{l}\text { Phrenic nerve \& CN XI } \rightarrow \text { Axillary nerve \& SSN } \\
\quad \text { most reliable }\end{array}$ \\
\hline Ogino \& Naito, 1995 & IV & 10 & Avulsion BPI & Intercostals $\rightarrow$ MCN \& median & $60 \%$ w/ M3 WF, 40\% w/ M3 FF \\
\hline Gu et al., 1990 & IV & 65 & Avulsion BPI & Phrenic nerve $\rightarrow$ MCN, various other & $84.6 \%$ functional recovery, no effect on respiration \\
\hline
\end{tabular}

$\mathrm{FF}=$ finger flexion; $\mathrm{ThF}=$ thumb flexion; $\mathrm{WF}=$ wrist flexion. 
root avulsions by reconstructing the spinal cord-nerve interface led by Carlstedt et al. ${ }^{24}$ using nerve root implantation or even nerve graft augmentation, ${ }^{6}$ the recovery results from these heroic attempts were meager compared with those of nerve transfers. Initially, nerve transfers were done for so-called irreversible brachial plexus injuries involving proximal nerve root avulsion from the spinal cord. More recently, many surgeons have turned to offering distal fascicular transfer as a preferred approach to manage more proximal brachial plexus injuries with a higher likelihood of functional recovery. Unfortunately, with the increasing utilization of distal nerve transfer techniques, there are many missed opportunities to evaluate and appropriately treat the area of the nerve injury zone itself. Indeed, the pooled analysis literature on brachial plexus repairs ${ }^{85}$ still underscores the fact that a nerve reconstruction at the level of the injury with grafting, along with the combination of targeted distal fascicular transfers, may offer the best possibility for recovery.

A further evolution of nerve transfer techniques involves the increasingly greater use of distal transfers to treat more proximal nerve injury such as injuries involving the ulnar, radial, and median nerves (see case examples in Fig. 2). ${ }^{13,60,65}$ Combinations of fascicular transfer distally from preserved branches of one of the aforementioned nerves to peripheral branches of the damaged nerve proximally are now being increasingly offered as an alternative to the classic tendon transfer techniques. In addition, many surgeons, led by Bertelli, ${ }^{12}$ are now recommending the combination of proximal nerve repairs (such as for high radial nerve injuries), with the augmentation of distal transfers from branches of the median nerve to the radial nerve to more reliably and quickly recover function such as finger extension. In the modern era, the peripheral nerve surgeon therefore has the exciting prospect of using exacting microsurgical techniques, aided by intraoperative electrophysiology along with the creative use of a wide combination or permutations of nerve transfer options.

\section{Nerve Transfers to Treat CNS Pathology}

A further extension of these transfer techniques has been to use them to augment and reanimate function in patients with spinal cord injuries as noted above. These entail transfers of nerve fascicles from preserved nerves above the level of the spinal cord lesion (so-called supralesional) to nerves at or below the level of the spinal cord injury (sublesional) in patients with complete quadriplegia. For example, in a complete C6 quadriplegia, a combination of transfer of the fascicle of the axillary nerve to triceps nerve can restore elbow extension and a fascicle from the radial nerve branch to the supinator to the PIN can reanimate finger extension, while finger flexion can be achieved by transferring a medial nerve branch to the pronator teres to the AIN for thumb and finger flexion (Fig. 3). This example represents a complete paradigm shift in that the surgeon uses a deliberate peripheral nerve rewiring procedure to overcome the neurological deficit imposed by a structural lesion in the CNS, in this case, the spinal cord. Recent attempts of similar procedures to reanimate the extremity in patients with central pathology such as hemispheric stroke have emerged. In a paper reported in the New England Journal of Medicine, pioneering work from China involved the transfer of the C7 spinal nerve root from the normal arm to the contralateral $\mathrm{C} 7$ of the paralyzed arm in an attempt to restore motor function and decrease spasticity in the paralyzed upper extremity from the stroke. ${ }^{87}$ The results were modest, and on editorial speculation, Spinner et al. noted that the results on the basis of the temporal kinetics of recovery were likely more on the basis of decreased inhibition and spasticity from neurotomy alone (of C7) rather than recovery on the basis of nerve regeneration. ${ }^{77}$ Whatever the mechanism, this clinical experience from the Chinese group nevertheless represents a bold direction in peripheral nerve surgery for the repair of CNS trauma.

\section{Future Perspectives}

The above review hopefully underscores the vast majority of choices available to reconstructive nerve surgeons to repair peripheral nerve injuries. Exploration, assessment, and nerve reconstruction of the original nerve injury remain the mainstay of surgical management. However, the increasing and appropriate use of distal targeted transfers along with central reeducation are becoming much more popular, even for injuries that were once considered for primary nerve repair.

The shift toward peripheral rewiring and central reeducation in our opinion will continue to evolve. We are already starting to see the next step in this revolution with the pioneering work of Aszmann et al., ${ }^{3}$ where a deliberate amputation of the paralyzed arm is done in a patient with intractable and nonrecovering severe brachial plexus injury with flail limb despite prior attempted nerve reconstruction. In patients exposed to prior intensive and systematic training, 2 reliable myoelectrical signals from the forearm are used to create movements in a prosthetic hand, specifically between the thumb and the other fingers. The patients were able to conduct new tasks (including bimanual performance) with the new prosthesis after amputation. Not only is it possible for these patients to gain some functional recovery of the limb but intriguingly there is a significant decrease in neuropathic pain in these patients, the mechanisms of which is not yet understood. Undoubtedly some degree of cortical plasticity and central rewiring is involved, and further research into the neuroanatomical, physiological, and mechanistic substrate is required to decipher this process. In the near future, with the further advent of robotic technology and with the improving understanding and incorporation of the brain-machine interface, we will undoubtedly see further evolution of peripheral rewiring procedures along with central reeducation to improve outcomes further.

\section{Acknowledgments}

We appreciate the assistance of Tak Ho Chu, $\mathrm{PhD}$, in helping render Figs. 2 and 3.

\section{References}

1. Ali ZS, Heuer GG, Faught RW, Kaneriya SH, Sheikh UA, Syed IS, et al: Upper brachial plexus injury in adults: com- 
parative effectiveness of different repair techniques. J Neurosurg 122:195-201, 2015

2. Anastakis DJ, Malessy MJ, Chen R, Davis KD, Mikulis D: Cortical plasticity following nerve transfer in the upper extremity. Hand Clin 24:425-444, vi-vii, 2008

3. Aszmann OC, Roche AD, Salminger S, Paternostro-Sluga T, Herceg M, Sturma A, et al: Bionic reconstruction to restore hand function after brachial plexus injury: a case series of three patients. Lancet 385:2183-2189, 2015

4. Baltzer HL, Kircher MF, Spinner RJ, Bishop AT, Shin AY: A comparison of outcomes of triceps motor branch-to-axillary nerve transfer or sural nerve interpositional grafting for isolated axillary nerve injury. Plast Reconstr Surg 138:256e264e, 2016

5. Bertelli JA: Transfer of the radial nerve branch to the extensor carpi radialis brevis to the anterior interosseous nerve to reconstruct thumb and finger flexion. J Hand Surg Am 40:323-328, 328.e1-328.e2, 2015

6. Bertelli JA, Ghizoni MF: Brachial plexus avulsion injury repairs with nerve transfers and nerve grafts directly implanted into the spinal cord yield partial recovery of shoulder and elbow movements. Neurosurgery 52:1385-1390, 2003

7. Bertelli JA, Ghizoni MF: Contralateral motor rootlets and ipsilateral nerve transfers in brachial plexus reconstruction. J Neurosurg 101:770-778, 2004

8. Bertelli JA, Ghizoni MF: Nerve root grafting and distal nerve transfers for C5-C6 brachial plexus injuries. J Hand Surg Am 35:769-775, 2010

9. Bertelli JA, Ghizoni MF: Nerve transfers for elbow and finger extension reconstruction in midcervical spinal cord injuries. J Neurosurg 122:121-127, 2015

10. Bertelli JA, Ghizoni MF: Nerve transfers for restoration of finger flexion in patients with tetraplegia. J Neurosurg Spine 26:55-61, 2017

11. Bertelli JA, Ghizoni MF: Reconstruction of C5 and C6 brachial plexus avulsion injury by multiple nerve transfers: spinal accessory to suprascapular, ulnar fascicles to biceps branch, and triceps long or lateral head branch to axillary nerve. J Hand Surg Am 29:131-139, 2004

12. Bertelli JA, Ghizoni MF: Results of nerve grafting in radial nerve injuries occurring proximal to the humerus, including those within the posterior cord. J Neurosurg 2016:179-185, 2016

13. Bertelli JA, Ghizoni MF: Transfer of a flexor digitorum superficialis motor branch for wrist extension reconstruction in C5-C8 root injuries of the brachial plexus: a case series. Microsurgery 33:39-42, 2013

14. Bertelli JA, Ghizoni MF: Transfer of supinator motor branches to the posterior interosseous nerve in C7-T1 brachial plexus palsy. J Neurosurg 113:129-132, 2010

15. Bertelli JA, Ghizoni MF: Transfer of the accessory nerve to the suprascapular nerve in brachial plexus reconstruction. $\mathbf{J}$ Hand Surg Am 32:989-998, 2007

16. Bertelli JA, Soldado F, Ghizoni MF, Rodríguez-Baeza A: Transfer of the musculocutaneous nerve branch to the brachialis muscle to the triceps for elbow extension: anatomical study and report of five cases. J Hand Surg Eur Vol 42:710714, 2017

17. Bertelli JA, Tacca CP, Ghizoni MF, Kechele PR, Santos MA: Transfer of supinator motor branches to the posterior interosseous nerve to reconstruct thumb and finger extension in tetraplegia: case report. J Hand Surg Am 35:1647-1651, 2010

18. Bhandari PS, Deb P: Use of contralateral spinal accessory nerve for ipsilateral suprascapular neurotization in global brachial plexus injury: a new technique. J Neurosurg Spine 24:186-188, 2016

19. Bhandari PS, Sadhotra LP, Bhargava P, Bath AS, Mukherjee MK, Bhatti T, et al: Surgical outcomes following nerve transfers in upper brachial plexus injuries. Indian J Plast Surg 42:150-160, 2009
20. Bhatia A, Doshi P, Koul A, Shah V, Brown JM, Salama M: Contralateral C-7 transfer: is direct repair really superior to grafting? Neurosurg Focus 43(1):E3, 2017

21. Brandt KE, Mackinnon SE: A technique for maximizing biceps recovery in brachial plexus reconstruction. J Hand Surg Am 18:726-733, 1993

22. Brushart T: Nerve Repair. Oxford: Oxford University Press, 2011

23. Cardenas-Mejia A, O'Boyle CP, Chen KT, Chuang DC: Evaluation of single-, double-, and triple-nerve transfers for shoulder abduction in 90 patients with supraclavicular brachial plexus injury. Plast Reconstr Surg 122:1470-1478, 2008

24. Carlstedt T, Anand P, Hallin R, Misra PV, Norén G, Seferlis $\mathrm{T}$ : Spinal nerve root repair and reimplantation of avulsed ventral roots into the spinal cord after brachial plexus injury. J Neurosurg 93 (2 Suppl):237-247, 2000

25. Cho AB, Iamaguchi RB, Silva GB, Paulos RG, Kiyohara LY, Sorrenti L, et al: Intercostal nerve transfer to the biceps motor branch in complete traumatic brachial plexus injuries. Microsurgery 35:428-431, 2015

26. Cho AB, Paulos RG, de Resende MR, Kiyohara LY, Sorrenti L, Wei TH, et al: Median nerve fascicle transfer versus ulnar nerve fascicle transfer to the biceps motor branch in C5-C6 and C5-C7 brachial plexus injuries: nonrandomized prospective study of 23 consecutive patients. Microsurgery 34:511-515, 2014

27. Chuang DC, Lee GW, Hashem F, Wei FC: Restoration of shoulder abduction by nerve transfer in avulsed brachial plexus injury: evaluation of 99 patients with various nerve transfers. Plast Reconstr Surg 96:122-128, 1995

28. Chuang DC, Yeh MC, Wei FC: Intercostal nerve transfer of the musculocutaneous nerve in avulsed brachial plexus injuries: evaluation of 66 patients. J Hand Surg Am 17:822-828, 1992

29. Coulet B, Boretto JG, Lazerges C, Chammas M: A comparison of intercostal and partial ulnar nerve transfers in restoring elbow flexion following upper brachial plexus injury (C5C6 \pm C7). J Hand Surg Am 35:1297-1303, 2010

30. Davidge KM, Yee A, Moore AM, Mackinnon SE: The supercharge end-to-side anterior interosseous-to-ulnar motor nerve transfer for restoring intrinsic function: clinical experience. Plast Reconstr Surg 136:344e-352e, 2015

31. El-Gammal TA, Fathi NA: Outcomes of surgical treatment of brachial plexus injuries using nerve grafting and nerve transfers. J Reconstr Microsurg 18:7-15, 2002

32. Ferraresi S, Garozzo D, Buffatti P: Reinnervation of the biceps in C5-7 brachial plexus avulsion injuries: results after distal bypass surgery. Neurosurg Focus 16(5):E6, 2004

33. Flores LP: Comparative study of nerve grafting versus distal nerve transfer for treatment of proximal injuries of the ulnar nerve. J Reconstr Microsurg 31:647-653, 2015

34. Flores LP: Outcomes of transferring a healthy motor fascicle from the radial nerve to a branch for the triceps to recover elbow extension in partial brachial plexus palsy. Neurosurgery 80:448-453, 2017

35. Flores LP: Transfer of a motor fascicle from the ulnar nerve to the branch of the radial nerve destined to the long head of the triceps for restoration of elbow extension in brachial plexus surgery: technical case report. Neurosurgery 70:E516E520, 2012

36. Flores LP, Socolovsky M: Phrenic nerve transfer for reconstruction of elbow extension in severe brachial plexus injuries. J Reconstr Microsurg 32:546-550, 2016

37. Friedman AH: An eclectic review of the history of peripheral nerve surgery. Neurosurgery 65 (4 Suppl):A3-A8, 2009

38. Garg R, Merrell GA, Hillstrom HJ, Wolfe SW: Comparison of nerve transfers and nerve grafting for traumatic upper plexus palsy: a systematic review and analysis. J Bone Joint Surg Am 93:819-829, 2011 
39. Goubier JN, Teboul F, Khalifa H: Reanimation of elbow extension with intercostal nerves transfers in total brachial plexus palsies. Microsurgery 31:7-11, 2011

40. Gu YD, Wu MM, Zhen YL, Zhao JA, Zhang GM, Chen DS, et al: Phrenic nerve transfer for treatment of root avulsion of the brachial plexus. Chin Med J (Engl) 103:267-270, 1990

41. Hua XY, Liu B, Qiu YQ, Tang WJ, Xu WD, Liu HQ, et al: Long-term ongoing cortical remodeling after contralateral C-7 nerve transfer. J Neurosurg 118:725-729, 2013

42. Kim DH, Midha R, Murovic JA, Spinner RJ: Kline and Hudson: Nerve Injuries, ed 2. Philadelphia: Elsevier, 2008

43. Kiwerski J: Recovery of simple hand function in tetraplegia patients following transfer of the musculo-cutaneous nerve into the median nerve. Paraplegia 20:242-247, 1982

44. Kline DG, Hackett ER, May PR: Evaluation of nerve injuries by evoked potentials and electromyography. J Neurosurg 31:128-136, 1969

45. Kline DG, Tiel RL: Direct plexus repair by grafts supplemented by nerve transfers. Hand Clin 21:55-69, vi, 2005

46. Kostas-Agnantis I, Korompilias A, Vekris M, Lykissas M, Gkiatas I, Mitsionis G, et al: Shoulder abduction and external rotation restoration with nerve transfer. Injury 44:299-304, 2013

47. Leechavengvongs S, Witoonchart K, Uerpairojkit C, Thuvasethakul P: Nerve transfer to deltoid muscle using the nerve to the long head of the triceps, part II: a report of 7 cases. $\mathbf{J}$ Hand Surg Am 28:633-638, 2003

48. Leechavengvongs S, Witoonchart K, Uerpairojkit C, Thuvasethakul P, Ketmalasiri W: Nerve transfer to biceps muscle using a part of the ulnar nerve in brachial plexus injury (upper arm type): a report of 32 cases. J Hand Surg Am 23:711-716, 1998

49. Leechavengvongs $\mathrm{S}$, Witoonchart $\mathrm{K}$, Uerpairojkit $\mathrm{C}$, Thuvasethakul P, Malungpaishrope K: Combined nerve transfers for C5 and C6 brachial plexus avulsion injury. J Hand Surg Am 31:183-189, 2006

50. Li W, Wang S, Zhao J, Rahman MF, Li Y, Li P, et al: Complications of contralateral C-7 transfer through the modified prespinal route for repairing brachial plexus root avulsion injury: a retrospective study of 425 patients. J Neurosurg 122:1421-1428, 2015

51. Lin H, Hou C, Chen D: Full-length phrenic nerve transfer as the treatment for brachial plexus avulsion injury to restore wrist and finger extension. Muscle Nerve 45:39-42, 2012

52. Mackinnon SE, Novak CB, Myckatyn TM, Tung TH: Results of reinnervation of the biceps and brachialis muscles with a double fascicular transfer for elbow flexion. J Hand Surg Am 30:978-985, 2005

53. Maldonado AA, Kircher MF, Spinner RJ, Bishop AT, Shin AY: Free functioning gracilis muscle transfer versus intercostal nerve transfer to musculocutaneous nerve for restoration of elbow flexion after traumatic adult brachial pan-plexus injury. Plast Reconstr Surg 138:483e-488e, 2016

54. Martins RS, Siqueira MG, Heise CO, Foroni L, Teixeira MJ: A prospective study comparing single and double fascicular transfer to restore elbow flexion after brachial plexus injury. Neurosurgery 72:709-715, 2013

55. Merrell GA, Barrie KA, Katz DL, Wolfe SW: Results of nerve transfer techniques for restoration of shoulder and elbow function in the context of a meta-analysis of the English literature. J Hand Surg Am 26:303-314, 2001

56. Millesi H, Meissl G, Berger A: The interfascicular nervegrafting of the median and ulnar nerves. J Bone Joint Surg Am 54:727-750, 1972

57. Mohanty CB, Bhat D, Devi BI: Role of central plasticity in the outcome of peripheral nerve regeneration. Neurosurgery 77:418-423, 2015

58. Nagano A, Ochiai N, Okinaga S: Restoration of elbow flexion in root lesions of brachial plexus injuries. J Hand Surg Am 17:815-821, 1992
59. Nagano A, Yamamoto S, Mikami Y: Intercostal nerve transfer to restore upper extremity functions after brachial plexus injury. Ann Acad Med Singapore 24 (4 Suppl):42-45, 1995

60. Novak CB, Mackinnon SE: Distal anterior interosseous nerve transfer to the deep motor branch of the ulnar nerve for reconstruction of high ulnar nerve injuries. J Reconstr Microsurg 18:459-464, 2002

61. Novak CB, Mackinnon SE, Tung TH: Patient outcome following a thoracodorsal to musculocutaneous nerve transfer for reconstruction of elbow flexion. Br J Plast Surg 55:416419, 2002

62. Nulsen FE, Slade HW: Recovery following injury to the brachial plexus, in Woodhall B, Beebe G (eds): Peripheral Nerve Regeneration: A Follow-Up Study of 3656 World War II Injuries. Washington, DC: US Government Printing Office, 1957, pp 389-408

63. Oberlin C, Béal D, Leechavengvongs S, Salon A, Dauge MC, Sarcy JJ: Nerve transfer to biceps muscle using a part of ulnar nerve for C5-C6 avulsion of the brachial plexus: anatomical study and report of four cases. J Hand Surg Am 19:232-237, 1994

64. Ogino T, Naito T: Intercostal nerve crossing to restore elbow flexion and sensibility of the hand for a root avulsion type of brachial plexus injury. Microsurgery 16:571-577, 1995

65. Phillips BZ, Franco MJ, Yee A, Tung TH, Mackinnon SE, Fox IK: Direct radial to ulnar nerve transfer to restore intrinsic muscle function in combined proximal median and ulnar nerve injury: case report and surgical technique. J Hand Surg Am 39:1358-1362, 2014

66. Ray WZ, Pet MA, Yee A, Mackinnon SE: Double fascicular nerve transfer to the biceps and brachialis muscles after brachial plexus injury: clinical outcomes in a series of 29 cases. J Neurosurg 114:1520-1528, 2011

67. Sallam AA, El-Deeb MS, Imam MA: Nerve transfer versus nerve graft for reconstruction of high ulnar nerve injuries. $\mathbf{J}$ Hand Surg Am 42:265-273, 2017

68. Samardzic M, Grujicic D, Antunovic V: Nerve transfer in brachial plexus traction injuries. J Neurosurg 76:191-197, 1992

69. Schreiber JJ, Byun DJ, Khair MM, Rosenblatt L, Lee SK, Wolfe SW: Optimal axon counts for brachial plexus nerve transfers to restore elbow flexion. Plast Reconstr Surg 135:135e-141e, 2015

70. Schreiber JJ, Feinberg JH, Byun DJ, Lee SK, Wolfe SW: Preoperative donor nerve electromyography as a predictor of nerve transfer outcomes. J Hand Surg Am 39:42-49, 2014

71. Sedain G, Sharma MS, Sharma BS, Mahapatra AK: Outcome after delayed Oberlin transfer in brachial plexus injury. Neurosurgery 69:822-828, 2011

72. Shapira Y, Midha R: Pathophysiology of surgical nerve disorders, in Filler A, Belzberg AJ, Chen L, Malessy M (eds): Youmans and Winn's Neurological Surgery, ed 7. Philadelphia: Elsevier, 2017, Vol 3, pp 1966-1977

73. Socolovsky M, Malessy M, Lopez D, Guedes F, Flores L: Current concepts in plasticity and nerve transfers: relationship between surgical techniques and outcomes. Neurosurg Focus 42(3):E13, 2017

74. Socolovsky M, Martins RS, Di Masi G, Siqueira M: Upper brachial plexus injuries: grafts vs ulnar fascicle transfer to restore biceps muscle function. Neurosurgery 71 (2 Suppl Operative):ons227-ons 232,2012

75. Soldado F, Ghizoni MF, Bertelli J: Thoracodorsal nerve transfer for triceps reinnervation in partial brachial plexus injuries. Microsurgery 36:191-197, 2016

76. Songcharoen P, Mahaisavariya B, Chotigavanich C: Spinal accessory neurotization for restoration of elbow flexion in avulsion injuries of the brachial plexus. J Hand Surg Am 21:387-390, 1996

77. Spinner RJ, Shin AY, Bishop AT: Rewiring to regain function 
in patients with spastic hemiplegia. N Engl J Med 378:8384,2018

78. Sungpet A, Suphachatwong C, Kawinwonggowit V: Onefascicle median nerve transfer to biceps muscle in C5 and C6 root avulsions of brachial plexus injury. Microsurgery 23:10-13, 2003

79. Terzis JK, Kokkalis ZT: Selective contralateral C7 transfer in posttraumatic brachial plexus injuries: a report of 56 cases. Plast Reconstr Surg 123:927-938, 2009

80. Terzis JK, Kostas I, Soucacos PN: Restoration of shoulder function with nerve transfers in traumatic brachial plexus palsy patients. Microsurgery 26:316-324, 2006

81. Wang S, Yiu HW, Li P, Li Y, Wang H, Pan Y: Contralateral C7 nerve root transfer to neurotize the upper trunk via a modified prespinal route in repair of brachial plexus avulsion injury. Microsurgery 32:183-188, 2012

82. Wang SF, Li PC, Xue YH, Yiu HW, Li YC, Wang HH: Contralateral C7 nerve transfer with direct coaptation to restore lower trunk function after traumatic brachial plexus avulsion. J Bone Joint Surg Am 95:821-827, S1-S2, 2013

83. Xiao C, Lao J, Wang T, Zhao X, Liu J, Gu Y: Intercostal nerve transfer to neurotize the musculocutaneous nerve after traumatic brachial plexus avulsion: a comparison of two, three, and four nerve transfers. J Reconstr Microsurg 30:297-304, 2014

84. Xu L, Gu Y, Xu J, Lin S, Chen L, Lu J: Contralateral C7 transfer via the prespinal and retropharyngeal route to repair brachial plexus root avulsion: a preliminary report. Neurosurgery 63:553-559, 2008

85. Yang LJ, Chang KW, Chung KC: A systematic review of nerve transfer and nerve repair for the treatment of adult upper brachial plexus injury. Neurosurgery 71:417-429, 2012

86. Yu A, Wang S, Cheng X, Liang W, Bai R, Xue Y, et al: Functional connectivity of motor cortical network in patients with brachial plexus avulsion injury after contralateral cervical nerve transfer: a resting-state fMRI study. Neuroradiology 59:247-253, 2017

87. Zheng MX, Hua XY, Feng JT, Li T, Lu YC, Shen YD, et al: Trial of contralateral seventh cervical nerve transfer for spastic arm paralysis. N Engl J Med 378:22-34, 2018

\section{Disclosures}

The authors report no conflict of interest concerning the materials or methods used in this study or the findings specified in this paper.

\section{Author Contributions}

Conception and design: Midha. Analysis and interpretation of data: Grochmal. Drafting the article: both authors. Critically revising the article: Midha. Reviewed submitted version of manuscript: Midha. Approved the final version of the manuscript on behalf of both authors: Midha.

\section{Correspondence}

Rajiv Midha: University of Calgary \& Foothills Medical Centre, Calgary, AB, Canada.rajmidha@ucalgary.ca. 